\title{
Hepatic infarction induced by HELLP syndrome: a case report and review of the literature
}

\author{
Qinyue Guo ${ }^{1 \dagger}$, Zhengfei Yang ${ }^{2 \dagger}$, Jian Guo ${ }^{3}$, Lei Zhang ${ }^{1}$, Lan Gao ${ }^{1}$, Bo Zhou ${ }^{4^{*}}$ and Qindong Shi ${ }^{1^{*}}$
}

\begin{abstract}
Background: HELLP syndrome is a rare disease in China, and 20\% of patients with severe preeclampsia have been accompanied with HELLP syndrome, which is characterized by the presence of hemolysis, elevated liver enzymes and low platelet count.

Case presentation: In this case, we reported that a patient with preeclampsia was diagnosed with HELLP syndrome. Furthermore, hepatic infarction also was found via the computed tomographic (CT) images, which showed peripheral wedge-shaped inhomogeneous low attenuation in the right hepatic lobes via plain CT scan, and the low-density shadow and mottled appearance in the same areas where vessels were seen coursing through them via contrast-enhanced $\mathrm{CT}$ scan.

Conclusions: Besides typical clinical manifestations of the pregnant patient with preeclampsia, the typical laboratory evidences were elevated liver enzymes and thrombocytopenia. The abdominal CT scan showed imaging features of hepatic infarction, which was helpful to identify the rare complication of HELLP syndrome. Thus, we diagnosed a patient with HELLP syndrome with hepatic infarction, though the patient had no chance to do the liver biopsy.
\end{abstract}

Keywords: Preeclampsia, HELLP syndrome, Hepatic infarct

\section{Background}

Preeclampsia (PE) is a pregnancy specific disorder which is characterized by new onset hypertension and proteinuria after the 20th weeks of gestation $[1,2]$. In the most severe form of preeclampsia, the presence of HELLP syndrome (defined as: hemolysis, elevated liver enzymes and low platelet) with the addition of hepatic compromise [3], such as hepatic infarction or hematoma [4, 5], increased the risk of maternal morbidity and mortality [6].

HELLP syndrome should be carefully distinguished with the diseases, such as benign thrombocytopenia of pregnancy and virus hepatitis. It's very important to identify the diagnosis of HELLP syndrome from other

\footnotetext{
* Correspondence: zb_bob@stu.xjtu.edu.cn; leonqind@163.com

${ }^{+}$Qinyue Guo and Zhengfei Yang contributed equally to this work.

${ }^{4}$ Department of Respiratory Medicine, the First Affiliated Hospital of Xi'an Jiaotong University, Xi'an, China

'Department of Critical Care Medicine, the First Affiliated Hospital of Xi'an Jiaotong University, 277 Yanta West Road, Xi'an 710061, Shaanxi, China Full list of author information is available at the end of the article
}

differential diagnosis. Once a clinical diagnosis of HELLP syndrome has been confirmed, it need aggressive interventions with control blood pressure, anti-seizure prophylaxis, corticosteroid treatment for fetal lung maturity enhancement, and expeditious delivery [7]. This case was collected in the First Affiliated Hospital of Xi'an Jiaotong University in China.

\section{Case presentation}

A 31-year-old pregnant patient, with a history of two pregnancy losses at first half of pregnancy and no history of autoimmune or thromboembolic diseases, was evaluated at $33+4$ weeks of gestation. An episode of symptomatic renal lithiasis requiring placement of double J stent at 3rd week of gestation was reported by the patient at admission.

The patient was admitted in local hospital due to dizziness, headache and blurred version,and worsening lower extremity edema 10 days ago. Examination results showed blood pressure 170/100 $\mathrm{mmHg}$, proteinuria 3+ and occult blood $3+$ by urinalysis. Immediate caesarean

(c) The Author(s). 2018 Open Access This article is distributed under the terms of the Creative Commons Attribution 4.0 International License (http://creativecommons.org/licenses/by/4.0/), which permits unrestricted use, distribution, and 
section was taken as diagnosed with severe preeclampsia. After the surgery, laboratory tests displayed elevated liver enzyme levels: peak aspartate transaminase (AST) and alanine transaminase (ALT) $(1758 \mathrm{u} / \mathrm{L}$ and $2158 \mathrm{u} / \mathrm{L}$ respectively), decreased platelet count $\left(20 \times 10^{9} / \mathrm{L}\right)$ and hemoglobin value $(65 \mathrm{~g} / \mathrm{L})$, increased white blood cells (WBC) $\left(27.45 \times 10^{9} / \mathrm{L}\right)$ and serum creatinine $(233 \mathrm{umol} / \mathrm{L})$ and urea $(31.6 \mathrm{mmol} / \mathrm{L})$. Symptomatic treatments were ineffective, so the patient was transferred to our hospital with the primary diagnosis of HELLP syndrome and severe preeclampsia.

On admission, the condition of the patient had worsened, and the heart rate was 120 beats per minute, the blood pressure was $138 / 74 \mathrm{mmHg}$ (controlled by nitroprusside), and the temperature was $36.5{ }^{\circ} \mathrm{C}$. The pitting ankle edema, headache and blurred version had gradually worsened accompanied with abdominal distension and weak chest, and decreased urine output. On physical examination, she appeared to be acutely ill with decreased breath sounds, the results of laboratory tests were not significantly improved than before, accompanied with negative urobilinogen, total bilirubin $25.5 \mathrm{umol} / \mathrm{L}$ and reduced serum albumin (Table 1 ). The ultrasonic images of hepatic parenchyma were abnormal, which may result from blood supply deficiency, and massive hydrothorax and ascites. Based on all above, we diagnosed the patient as HELLP syndrome, but could not fully rule out other diseases with similar symptoms. The therapy including continuous renal replacement therapy (CRRT), plasma exchange and other supportive treatments such as red cell transfusion, platelet concentrates transfusions and antihypertensive were provided for the patient immediately.

Three days after admission to our hospital, plain CT scan showed peripheral wedge-shaped inhomogeneous low attenuation in the right hepatic lobes (Fig. 1a), and the lowdensity shadow and mottled appearance in the same areas where vessels were seen coursing through them via contrast-enhanced CT scan (Fig. 1b). Base on CT images, liver infarction was diagnosed. Further tests showed that amylase in plasma and urine was negative, and hepatitis B antigens and antibody, and hepatitis A antibody were all negative, and the levels of glucose and blood ammonia were normal. Therefore, we further confirmed the diagnosis HELLP syndrome with liver infarction.

Then we continued treating the patient with antibiotics, CRRT, drainage of pleural effusion and ascites, and the supportive treatments. Intravenous dexamethasone $10 \mathrm{mg} / \mathrm{d}$ for 3 days was initiated. The results of laboratory tests were normalized within 17 days. The damaged areas were recovered on 17th days after admission via the second enhanced CT (Fig. 1c and d). She remained asymptomatic and had no complications during 6 months of follow-up.

\section{Discussion and conclusions}

In this case, we reported that a pregnant woman with preeclampsia was diagnosed with HELLP syndrome (Hemolysis, increased liver enzyme, and low platelets count). Furthermore, hepatic infarction also found via the computed tomographic (CT) images, which showed peripheral wedge-shaped inhomogeneous areas of low attenuation in the right hepatic lobes via plain CT scan, and the low-density shadow and mottled appearance in the same areas where vessels were seen coursing through them via contrast-enhanced CT scan. Thus, the case of HELLP syndrome is rare to be found accompanied with liver infarction. Abdominal CT is often helpful for the management of HELLP syndrome to rule out hepatic hematoma, and in this case, we found that liver infarction was induced by HELLP syndrome.

Liver infarction is a very rare event because of hepatic distinct double blood supply. Most cases of liver infarction result from interference with arterial blood supply to the liver, due to pregnancy-induced hypertension

Table 1 laboratory and blood chemical findings

\begin{tabular}{llll}
\hline & Local hospital & 3th hospital day & 17th hospital day \\
\hline Glucose & Normal & Normal & Normal \\
Proteinuria & $3+$ & $3+$ & Normal \\
Aspartate transaminase $(\mathrm{AST})(\mathrm{U} / \mathrm{l})$ & 1758 & 85 & 12 \\
Alanine transaminase $(\mathrm{ALT})(\mathrm{U} / \mathrm{l})$ & 2158 & 98 & 10 \\
Total bilirubin $(\mathrm{umol} / \mathrm{L})$ & 27.5 & 24 & 12 \\
White blood cells $(\mathrm{WBC})\left({ }^{*} 10^{9} / \mathrm{L}\right)$ & 27.5 & 32.6 & 3.7 \\
Hemoglobin $(\mathrm{g} / \mathrm{L})$ & 65 & 65 & 81 \\
Platelet count $\left(* 10^{9} / \mathrm{L}\right)$ & 20 & 26 & 155 \\
Serum creatinine $(\mathrm{umol} / \mathrm{L})$ & 233 & 135 & 81 \\
Urea $(\mathrm{mmol} / \mathrm{L})$ & 31.6 & 11.6 & 3.6 \\
Cholesterol $(\mathrm{mmol} / \mathrm{L})$ & 4.09 & 2.99 & 3.05 \\
Triglycerides $(\mathrm{mmol} / \mathrm{L})$ & 3.31 & 2.01 & 1.70 \\
\hline
\end{tabular}




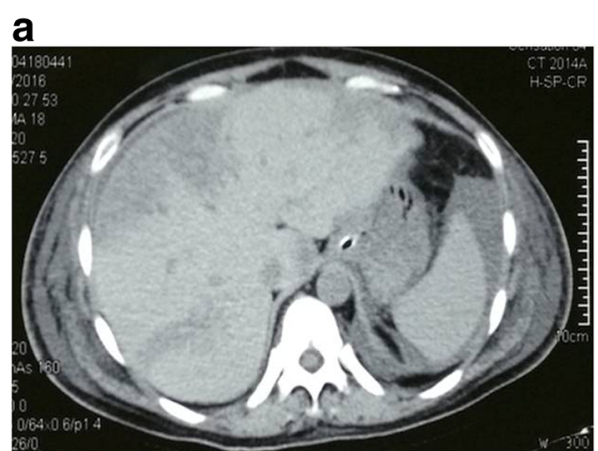

C

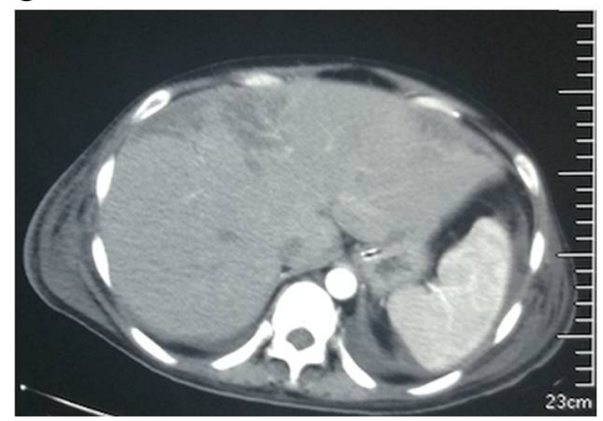

b

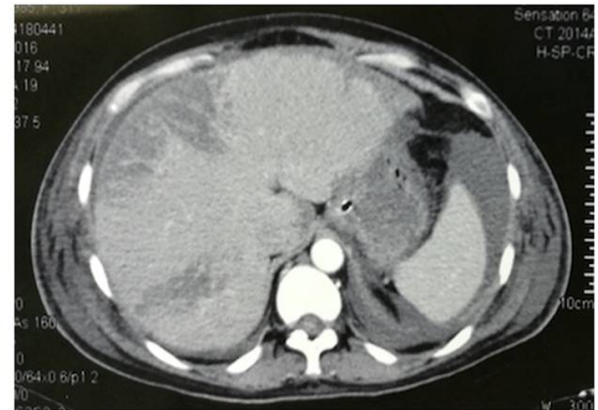

d

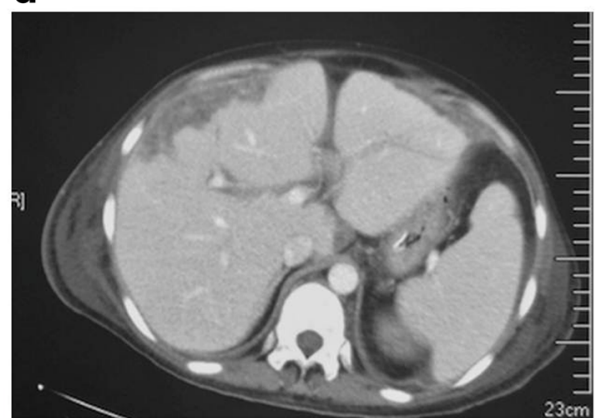

Fig. 1 a Non-contras $C T$ demonstrates peripheral wedge-shaped inhomogeneous low attenuation in the right hepatic lobes on 3th after admission. b Contrast-enhanced CT of the liver shows mottled appearance in the same areas where vessels were seen coursing through. $\mathbf{c}$ and $\mathbf{d}$ showed the damaged areas were reduced in the enhanced $C T 17$ th days after admission

(PIH), anti-phospholipid syndrome (APS), ischemic hepatitis, and portal vein thrombosis (PVT) and so on $[8,9]$. Clinical manifestations of liver infarction are nonspecificity, suddenly upper abdominal pain, fever, jaundice, and suddenly increased liver aminotransferases. The liver biopsy is helpful to distinguish liver infarction from other diseases such as liver abscess or cholangiocarcinoma, while, imaging examination also play an important role in diagnosis. Although hepatic infarction is nonspecific and may be caused by a variety of diseases, the CT images of the liver appear to be helpful for the differential diagnosis of liver dysfunction. A few cases of liver infarction induced by HELLP syndrome have been reported in China [10].

HELLP syndrome happened in about $20 \%$ of patients with severe preeclampsia [11]. The diagnosis of HELLP syndrome could be made through typical results of laboratory tests, including signs of hemolytic anemia and thrombocytopenia with platelets $<100,000$ cells/ul, elevated AST, ALT and lactate dehydrogenase, associated with clinical manifestation of right upper quadrant pain, nausea, vomiting, malaise, headache and edema, but some women with HELLP syndrome may be asymptomatic.

In this case, proteinuria, pregnancy-induced hypertension, edema, elevated liver enzyme levels, decreased platelet count and hemoglobin, rapidly increased serum creatinine and urea all supported the criteria for both PE and HELLP syndrome [12], but the pathogenesis of both PE and HELLP is still unknown. Fortunately, CRRT and plasma exchange were effective for the patient, and after hormone therapy and supportive treatments, the damaged areas of liver were recovered and the patient got better.

Liver infarction is rare with the consequences of HELLP syndrome [13]. CT scan may be a useful method for the differential diagnosis, which showed peripherally wedge-shaped inhomogeneous areas of low attenuation with enhanced vessels coursing through these areas. Based on the clinical manifestation, the CT images, and other laboratory tests (For example the levels of glucose and blood ammonia are normal), we could rule out other diagnoses and make a definite diagnosis for HELLP syndrome with liver infarction.

In conclusion, we reported a patient diagnosed with the HELLP syndrome with hepatic infarction. The clinical manifestations of the pregnant patient with preeclampsia were headache, blurred version, abdominal distension and weak chest. The typical laboratory evidences were elevated liver enzymes, thrombocytopenia. Thus, we diagnosed the patient with the HELLP syndrome. The abdominal CT scan showed imaging features of hepatic infarction, which was helpful to identify the rare complication of HELLP syndrome. 


\section{Abbreviations}

AFLP: Acute fatty liver of pregnancy; ALT: Alanine transaminase; APS: Antiphospholipid syndrome; AST: Aspartate transaminase; CRRT: Continuous renal replacement therapy; CT: Computed tomographic; DIC: Disseminated intravascular coagulation; PE: Preeclampsia; PIH: Pregnancy-induced hypertension; PVT: Ischemic hepatitis, portal vein thrombosis; WBC: White blood cells

\section{Funding}

This work was supported by the programs Young Innovators Awards of the First Affiliated Hospital of Xi'an Jiaotong University (2015YK6) in the design of the study and collection, and Natural Science Foundation of Shaanxi province (2017JM8016) in analysis and interpretation of data.

\section{Availability of data and materials}

All data generated or analysed during this study are included in this published article.

\section{Authors' contributions}

ZY, JG, LZ and LG analyzed and interpreted the patient data. QG contributed to collection of data and writing of the manuscript. BZ contributed to support of funding and revision of manuscript. QS contributed to supervision of the research group and revision of manuscript. All authors read and approved the final manuscript.

\section{Ethics approval and consent to participate}

All procedures were performed in accordance with the guidelines in the Declaration of Helsinki, and were approved by the ethics committee, the First Affiliated Hospital of Xi'an Jiaotong University. The patient was treated solely according to standard treatment.

\section{Consent for publication}

Written informed consent was obtained from the patient for the publication of this case report and any accompanying images.

\section{Competing interests}

The authors declare that they have no competing interests.

\section{Publisher's Note}

Springer Nature remains neutral with regard to jurisdictional claims in published maps and institutional affiliations.

\section{Author details}

${ }^{1}$ Department of Critical Care Medicine, the First Affiliated Hospital of Xi'an Jiaotong University, 277 Yanta West Road, Xi'an 710061, Shaanxi, China. ${ }^{2}$ Sun Yat-sen Memorial Hospital, Sun Yat-sen University, Guangzhou, China. ${ }^{3}$ Department of Hepatobiliary Surgery, the First Affiliated Hospital of Xi'an Jiaotong University, Xi'an, China. ${ }^{4}$ Department of Respiratory Medicine, the First Affiliated Hospital of Xi'an Jiaotong University, Xi'an, China.

Received: 23 January 2017 Accepted: 30 April 2018

Published online: 30 May 2018

\section{References}

1. Sibai B, Dekker G, Kupferminc M. Pre-eclampsia. Lancet. 2005:365(9461):785.

2. Brown MA, et al. The classification and diagnosis of the hypertensive disorders of pregnancy: statement from the International Society for the Study of hypertension in pregnancy (ISSHP). Hypertens Pregnancy. 2001; 20(1):IX-XIV.

3. Sibai BM. Diagnosis, controversies, and management of the syndrome of hemolysis, elevated liver enzymes, and low platelet count. Obstet Gynecol. 2004;103(1):981-91.

4. Hay JE. Liver disease in pregnancy. Hepatology. 2008;47(3):1067-76.

5. Tran T, Ahn J, Reau NS. ACG clinical guideline: liver disease and pregnancy. Am J Gastroenterol. 2016;111(2):176-94.

6. Haddad B, et al. Risk factors for adverse maternal outcomes among women with HELLP (hemolysis, elevated liver enzymes, and low platelet count) syndrome. Am J Obstet Gynecol. 2000;183(2):444-8.

7. Witlin AG, Saade GR, Mattar F, Sibai BM. Risk factors for abruption placentae and eclampsia: analysis of 445 consecutively managed women with severe preeclampsia and eclampsia. Am J Obstet Gynecol. 1999;180:1322-9.
8. Zissin R, Yaffe D, Fejgin M, et al. Hepatic infarction in preeclampsia as part of the HELLP syndrome: CT appearance. Abdom Imaging. 1999;24(6):594-6.

9. Miyakoshi K, Tanaka M, Ono A, et al. Massive hepatic infarction in preeclampsia: successful treatment with continuous hemodiafiltration and corticosteroid therapy. J Perinat Med. 2004;32(5):453.

10. Einar S, Kjell H, Ulrich A. The HELLP syndrome: clinical issues and management. A review. BMC Pregnancy Childbirth. 2009;9(1):8.

11. Kronthal AJ, Fishman EK, Kuhlman JE, et al. Hepatic infarction in preeclampsia. Radiology. 1990;177(177):726-8.

12. Ibdah JA. Acute fatty liver of pregnancy: an update on pathogenesis and clinical implications. World J Gastroenterol. 2007;12(46):7397-404.

13. Holbert BL, Baron RL, Dodd GD 3rd. Hepatic infarction caused by arterial insufficiency: spectrum and evolution of CT findings. Am J Roentgenol. 2013;166(4):815-20.

\section{Ready to submit your research? Choose BMC and benefit from:}

- fast, convenient online submission

- thorough peer review by experienced researchers in your field

- rapid publication on acceptance

- support for research data, including large and complex data types

- gold Open Access which fosters wider collaboration and increased citations

- maximum visibility for your research: over $100 \mathrm{M}$ website views per year

At BMC, research is always in progress.

Learn more biomedcentral.com/submissions 